\title{
Knowledge is power, and power needs knowledge
}

\author{
Pekka Sulkunen ${ }^{1}$ \\ ${ }^{1}$ Department of Sociology, University of Helsinki, Helsinki, Finland
}

In the years 2011-2015 I served on the expert committee of the foundation called ERAB, now a public charity, funded by the Brewers of Europe. Our task was to review grant applications to deliver half a million euros per year to research on alcohol consumption. There was no detectable indication that the proposals were biased to please the brewers, and certainly the decisions were not. However, things changed in 2015, when the Secretary General of the Brewers of Europe requested on behalf of the funders that $40 \%$ of the grant money should go to research aiming at "a better understanding of the effects of moderate beer consumption on the behaviour and health of individuals and society." This was unacceptable to all experts on the committee, and the Chair of the Board of ERAB resigned in protest. After a battle between the Brewers and the expert committee, the formulation laid down was "more research on beer.” I could not accept this either, arguing that any external criteria beyond the quality of the proposals undermined the scientific integrity of the selecting experts.

I am nevertheless against total refusal of industry funding for alcohol research. Conflicts between the interests of researchers and the interests of research funders may arise in several ways, but they depend on the terms and conditions of funding and its management.

Recently I had the good fortune to be a Fellow in the Helsinki Collegium for Advanced Studies. The grant was funded by the elevator company KONE through its foundation established for granting support for research in humanities and social sciences. The funder asked me to tell them about my research (which focused on addictions and had nothing to do with elevators) on two occasions, but they did not participate in the selection of the Fellows, nor did they supervise or use our work in any way. This is an extreme example of disinterested science sponsoring, with prestige as the funder's only reward for the donation.

My career in alcohol sociology started on a grant arranged by Kettil Bruun, then research director of the Finnish Foundation for Alcohol Studies, which was 100\% funded by the Finnish Alcohol Monopoly. The task was to provide a study of world trends in alcohol consumption, production and trade, to be used in the collaborative book Alcohol Policies in Public Health Perspective (Bruun et al., 1975) that used and stimulated research on what today is called the Total Consumption Model in alcohol policy. Bruun had serious conflicts with the Monopoly management over this model and the related research he advocated. The policy guidelines based on the model were against industry interests (Sulkunen \& Warsell, 2012). The reason he could carry on was that the board of the foundation was fortified against the funder's interests with representatives from academia, the Ministry that controlled the Monopoly, and the temperance movement still influential in Parliament at the time.

I chose these examples to highlight three points. The first is that the lines between acceptable and unacceptable interests of funders are often thin. The ERAB example shows how tricky situations arise when the sponsor directs prestige funds to areas of its own business activity, even when criteria of scientific quality are applied to assure a prestige value to the donation. The extreme form of abusing scientific legitimacy by industry is think-tanking to promote its interests with prestige funds from public research agencies (Miller \& Kypri, 2009). ERAB was thinking of applying for EU research funding. This was my second reason to quit.

The second lesson is that the less research is related to the field of corporate sponsors, the higher the prestige value of their contributions, but even then the funders should keep their hands off the selection, implementation, and use of research, as the KONE Foundation does.

The third lesson is that sometimes the funder's interests can be overridden when they conflict with the research that scientists feel worth pursuing, but this is a matter of institutional power. Such conflicts are very common in all public policy areas with research input from governmentcontrolled resources. This is the reason why state-funded social research institutes often fail when their governing bodies and key researchers are not sufficiently autonomous.

These points-autonomy of selecting bodies and researchers, relatedness to the field of business activity, and clear separation of prestige funds from business-oriented research and lobbying-may sound rather simple when applied to corporate sponsors, but they do apply also to public science funding. Voices are currently being raised 
for higher social impact and public utility of research, especially in social policy areas. The aim is understandable but the means can go wrong. "Strategic" or program-based science funding with policy objectives to guide research to desired areas, like most of the EU Framework Programmes, formulate research objectives in political and widely acceptable terms such as environmental sustainability, equality, technological innovation, health, safety and security, etc. These are detailed in expensive and timeconsuming negotiations to please interests that can afford lobbying, forcing applicants to use language that reflects political needs rather than concepts and methods required by the science. Such negotiations not only waste a lot of money but also violate the autonomy of researchers and selectors. Fortunately, the development of the European Research Council within the Horizon 2020 is an attempt to avoid these pitfalls with its "blue-sky" or science-based approach.

Knowledge is power, and power needs knowledge. Research always has to deal with this fact. Part of the power of knowledge derives from disinterest. Ethical problems arise when business or political interests try to free-ride on the prestige value of objective science, often exploiting public research funding institutes for this purpose. Strategic or program-based research funding by public bodies also involve ethical as well as management problems, most of them related to unequal resources for lobbying and politicians' unfamiliarity with the state of the art in the relevant research fields.

\section{References}

Bruun, K., Edwards, G., Lumio, M., Mäkelä, K., Pan, L., Popham, R. E., . . . Österberg, E. (1975). Alcohol control policies in public health perspective (Vol. 25). Helsinki, Finland: The Finnish Foundation for Alcohol Studies.

Miller, P., \& Kypri, K. (2009). Why we will not accept funding from Drinkwise. Drug and Alcohol Review, 28, 324-326. doi:10.1111/j.1465-3362.2009.00072.x

Sulkunen, P., \& Warsell, L. (2012). Universalism against particularism. Kettil Bruun and the ideological background of the Total Consumption Model. Nordic Journal of Alcohol and Drugs 29(3), 217-232. 